\title{
Legal Developments and Problems of the Bologna Process within the European Higher Education Area and European Integration
}

\author{
ROBERTO CIPPITANI and SUZANNE GATT
}

2010 sees the end of the process of establishing the European Higher Education Area (EHEA). Although not all countries may have achieved all the objectives, many are those countries and universities who have implemented many of the targets set. Within the Bologna Process, there have been many developments such as: European Credit Transfer and Accumulation System (ECTS) for the transfer of period of study abroad; joint degrees; and quality assurance aspects among others. Guidelines for Quality Assurance and the development of an overarching European Qualifications Framework have been developed. While the Bologna Process brings with it many advantages on an education level, the discussion has not really considered the legal aspects of such a system. Once the EHEA is implemented comprehensively across Europe, situations may arise which would require universities to consider the legal aspects of learning that students may have experienced within different tertiary institutions. This paper considers what problems may arise, for example with fraudulent behaviour by students in the acquisition of ECTS credits in another university; with weaknesses or failure to prove quality of learning following an external quality assurance audit in another university; with the failure to deliver learning by one of the partner universities running joint degrees etc., and explores the possible legal implications of such situations as well as identifying the legal lacunae which exist and which need to be taken into consideration if the EHEA is to maintain the reputation that it aims for.

\section{Introduction}

Universities play a major role within Europe in reaching the Lisbon target of making Europe a knowledge society. In the recognition that Europe must strengthen its three poles of the knowledge triangle: education, research and innovation; an argument is made in favour of investing more in the modernization and quality of universities for the future of Europe and Europeans (Commission of the European Communities, 2005). Research and Development, as well as universities are acknowledged as the foundations for European competitiveness. "The European dimension thus offers the potential benefits of larger scale operation, greater diversity and intellectual richness of resources, plus opportunities for cooperation and competition between institutions" (Commission of the European Communities, 2006, p. 2).

The European Commission thus calls for more autonomy to be given to universities. As stated by the Commissioner responsible for Education, Training, Culture and Multilinguism (Figel, 2005), Europe's higher education systems remain hampered by systems developed decades ago. The liberation of universities should also extend to their governance and universities need to improve their management of research and other activities, while public authorities focus on the strategic orientation of the system as a whole (Barroso, 2005). The aim to preserve universities at a national level has led to 
over-regulation and control, imposing a degree of uniformity which has resulted in fragmentation and difficulties in cooperating at national and European level (Commission of the European Communities, 2006). The European Commission thus calls for reinforcing the public responsibility for higher education as a system by defining a regulatory framework within which strategic orientation combined with autonomy and diversity results in wider access and higher quality. There is also the need to enable institutional modernization strategies which allow universities to respond quickly to society's needs and take full account for their responsibilities to be implemented (Commission of the European Communities, 2005).

A number of changes are required to achieve these goals and for universities to establish themselves within a knowledge-based society (Commission of the European Communities, 2006). A major effort needs to be made to achieve at least the core Bologna reforms by the established 2010. Universities need to develop new internal governance systems to overcome the fragmentation within their own structure. They need to recognise that their relationship with the business community is of strategic importance and is part of their commitment to serving the public interest. Universities need also to work for greater dialogue with society and other stakeholders. They need to give due importance to the promise that their programmes also aim to enhance the employability of their students, and that they need to promote an entrepreneurial mindset. Universities have to understand and provide opportunities to respond to the challenges that lifelong learning poses. They also need, in view of new economic trends, to review and possibly rethink their method of funding. There is also need to restructure their traditional makeup and move from less scientific-specific domains to more research domains allowing greater multi-disciplinarity, and to find ways to attract the best academics and researchers within the European Higher Education Area (EHEA) (Commission of the European Communities, 2006).

In working towards achieving these aims, many universities across Europe and beyond have been undergoing reforms as part of the implementation exercise of the Bologna Process. This has implied that universities have opened themselves to working with other entities on both national and transnational level. There is in-depth and coordinated change from the way in which systems are regulated and managed, to the ways in which universities are governed (European Commission, 2006). Consequently, whether it is a question of transfer of credits, collaborative research projects, joint degrees with businesses or other universities, universities have found themselves binding themselves in contractual agreements within the European legislative framework. They are also being required to fulfil quality assurance standards which are based on European rather than on national standards and which must comply with an overall European legislative framework. These changes bring with them legal implications which go beyond national frameworks. The Bologna Process has given great attention to educational and research aspects in ensuring a service of highest quality by European universities, and is working towards building over-arching legislative frameworks particularly in the area of recognition of qualifications and quality assurance systems within which universities will be required to operate within continued globalization. These require universities to act in new areas of legislation and which may give rise to particular problems of a legal nature which as yet have not cropped up as the system is not yet fully in place and operative. This paper aims to identify potential problems which may crop up and considers those legal aspects which would need to be given due attention within the Bologna Process in order to allow the EHEA and the European 
Research Area to be fully open to the world and become competitive worldwide players (Commission of the European Communities, 2006).

\section{A Historical Perspective of European Integration}

Europe has been, from medieval times to the present day, a place which fosters and nurtures the development of the rich intellectual and cultural community known as Europe. This can be stated despite the great cultural, geographical and political diversity that exists and which it enjoys, and which gives it its unique characteristic of being a cultural mix or "soup" (Morin, 1990) of ideas and experiences which can be at the same time antagonistic as well as not necessarily indigenous to Europe but which exemplify Europe. Intellectual Europe has deep roots, developing and growing considerably during the periods of the twelfth and thirteenth centuries due to the common Latin language (Ruberti, 1995), which allowed and promoted discussion and dialogue among intellectuals across Europe as well as the exploration and elaboration of areas of study such as philosophy, science, arts, and law.

One finds that Renaissance Europe experienced great changes or, as described by Morin (1990), "waves of new ideas". During this period one finds among the great and rich developments of European culture, the birth of science with its specific science method as we know it today. This places the development of science as a body of knowledge which has European rather than national roots. The development of science was the fruit of the work of scholars from all over Europe, rather than one particular nation, who together, through their philosophical and intellectual encounters and contributions, developed the scientific method which has allowed Europe to become the developed society that it is today.

The end of the Second World War and the reconstruction of a new Europe was a time when there was a great felt need to work on the integration of Europe. The post-war years led to the setting up of not only treaties between countries, but also of international organizations promoting collaboration through research. So one finds the inception and setting up of large research institutions such as the European Centre for Nuclear Research (CERN), which has the largest particle physics laboratory in the world; the European Space Agency (ESA) involved in space research and exploration; the European Southern Observatory (ESO) which operates a suite of the world's most advanced ground-based astronomical telescopes; the European Molecular Biology Organization (EMBO) promoting excellence in molecular life sciences in Europe; and the European Synchrotron Radiation Facility (ESRF) which is an international institute funded by nineteen countries and operating Europe's most powerful synchrotron light source.

Efforts for European integration have also been sustained in the area of culture and related areas. This European dimension is provided by the Council of Europe, whose aim is to achieve a greater unity between its members for the purpose of safeguarding and realizing the ideals and principles which are the common heritage and facilitate economic and social progress. Thus, joint initiatives can be found in the areas such as human rights, democracy, social cohesion, education, culture, youth etc.

The EU has a shorter history and was primarily set up fundamentally as a common economic area. It was only later that the idea of integration in other sectors other than the economic aspect was considered. It was with the Maastricht Treaty at the beginning of the 1990s that research, education and training were officially recognized as part of 
the responsibilities of the EU. This approach and realization resulted in the publication of the White Paper on Growth, Competitiveness and Employment (European Commission, 1993), which tackled the issues of mobility of goods, workers, and capital. Even though maybe still with economic aspects in mind, other issues relating to training, qualifications and other educational aspects came into play. This led to further developments with the publication of the White Paper on Education and Training: Lifelong Learning (European Commission, 1995b); and the Green Paper on Innovation (European Commission, 1995a). The intertwining and inseparable relationship between education and training and the European labour market led to the realization that Europe needs to consider the Integration of Education across Europe to ensure European economic success.

It is within this frame of mind that an extraordinary meeting of the European Council was held in Lisbon on 23-24 March 2000 and when the Lisbon Strategy, also known as the Lisbon Agenda or Lisbon Process to make the EU "the most dynamic and competitive knowledge-based economy in the world capable of sustainable economic growth with more and better jobs and greater social cohesion, and respect for the environment by 2010 " was conceptualized.

There have been a number of stumbling blocks in European integration on an economic level. One of these major obstacles emerges from the little consideration that was given to the diversity in the cultural aspects of the integration process. This led to the realization that Europe does not have a European Education system, a European policy for research and innovation, or a policy on ethics and the environment, making Europe detached from the everyday lives of its citizens. Cippitani (2005) highlights a number of problems within the EU at this point in time. Among the factors identified, one finds rigid and closed education systems. This reflects the dichotomy that has developed with time between education and training, more known as tertiary and vocational education. With respect to research and innovation, there was a lack of resources for research; insufficient technology transfer; fragmentation; and lack of coordination. In addition, emergent problems included the social and ethical implications of scientific research such as cloning and stem cell research as well as the ever-growing environmental problems. On a legal aspect, the EU was facing a situation of democratic deficit, and on top of all this, there was also the problem of unemployment and social exclusion which in a way tied all these aspects together.

\section{Developments within the Bologna Process from a Legislative Perspective}

The Bologna Process was not an initiative of the European Commission but the result of a need shared by a number of ministers responsible for higher education in the European countries: France, Italy, the United Kingdom and Germany who met in 1998. Within all the reality of the problems that the EU was encountering as part of the integration process, these ministers recognized the need for restructuring higher education across Europe. This resulted in the Sorbonne Declaration (European Ministers in Charge of Higher Education, 1998) which tackled the "harmonisation of the architecture of the European Higher Education system'. In the Sorbonne Declaration, the signatory countries agreed to work together towards having: a convergence of the overall Higher Education framework and cycle in an open EHEA; a common degree level system for 
undergraduates (Bachelor's degree) and graduates (Master's and Doctorate degrees); and enhancing student and teacher mobility, removing obstacles for mobility and improving recognition of degrees and academic qualifications.

The initiatives were viewed positively by a number of other countries leading, just one year later, in 1999, to twenty-nine other European ministers in charge of higher education meeting in Bologna and signing the Bologna Declaration (European Ministers in Charge of Higher Education, 1999). This declaration lays the basis for establishing a EHEA by 2010. The Bologna Declaration listed six key issues: adopting a system of easily readable and comparable degrees; adopting a system of two main cycles (undergraduate/graduate); establishing a system of credits (such as European Credit Transfer and Accumulation System [ECTS]); promoting mobility by overcoming obstacles; promoting European co-operation in quality assurance; and promoting a European dimension in higher education.

The approach to be taken was a bottom-up approach as it was felt that the key players in each country and university would know best how to work on these issues. In the Prague Communiqué (European Ministers in Charge of Higher Education, 2001) the active involvement of the European University Association (EUA) and the National Unions of Students in Europe (ESIB, later ESU) was recognized as crucial to the process, as was the constructive assistance of the European Commission in the process. The Prague Communique emphasized the important elements of the EHEA to include lifelong education; the active involvement of students; and the need to enhance the attractiveness and competitiveness of the EHEA to other parts of the world beyond Europe. In all these aspects, one can see the recognition of the need for inclusion of all the different players. If European integration were to take place, there was a need for all the different players to come and work together, to communicate and to try and find solutions to the obstacles as one single European group. Having said this, it is also evident that the main focus was and still remains the education and political aspect of the investment in integrating the EHEA. The legal implications that the new university structures as well as types of collaboration in research and joint periods of study, whether for period of mobility such as the ERASMUS exchange, or the issuing of joint degrees, called for the development of an overall European legislative framework.

Further developments within the Bologna Process showed a need to ensure that universities do actually offer the quality of education that the EHEA promises. It also reflected a legislative need to ensure that all universities, as legal entities, would be providing the quality education that the EHEA was offering. Thus, the resulting great emphasis on quality assurance which was recognized as part of the Berlin Communique (European Ministers in Charge of Higher Education, 2003) in conjunction with the development of the two-cycle system, and the need to promote the recognition of degrees and periods of study.

Another legislative issue which was gaining importance within the whole process was the recognition of qualifications within the EHEA and beyond. There was a need to provide recognition on a legal aspect. This is the role which led to the pressure for all member states and other Bologna signatories to sign the "Council of Europe/UNESCO Convention on the Recognition of Qualifications Concerning Higher Education in the European Region (Lisbon Convention)" (Council of Europe/UNESCO, 1997) as well as the additional texts on: the "Recommendation on International Access Qualifications" adopted by the Intergovernmental Committee of the Lisbon Recognition Convention in 
Vilnius on 16 June 1999; Recommendation on the Criteria and Procedures for the Assessment of Foreign Qualifications and Periods of Study (2001); the "Code of Good Practice in the Provision of Transnational Education" adopted by the Lisbon Recognition Convention Committee at its second meeting in Riga (6 June 2001); and the Recommendation on the Recognition of Joint Degrees (2004). All these are international legal texts. Conventions are the most legally binding and standard setting texts which bind parties (governments) to fulfil the obligations specified in a treaty as legal obligations and competent authorities within countries can be held legally accountable if obligations are not observed (Council of Europe, 2005). The Recognition Convention offers a number of benefits to individuals in that holders of qualifications in one country should have adequate access to an assessment of these qualifications in another country and ensures that no discrimination on grounds of gender, race, colour, disability, language, religion, political opinion, national, ethnic or social origin take place. It also states that the recognition of foreign qualifications should entitle individuals to have access to further higher education and/or an academic title, as well as to access to the labour market depending on the qualifications involved. It also lays down obligations to governments to develop procedures to assist persons to fulfil the relevant requirements for access to higher education, information about institutions offering higher education, of having a national information centre, as well as encouraging institutions to offer a Diploma Supplement to students to facilitate recognition (Council of Europe, 2005).

The Bergen Communiqué (European Ministers in Charge of Higher Education, 2005) underlined the complementarities between the overarching framework for the EHEA and the broader framework of qualifications for lifelong learning encompassing both general and vocational education. The Ministers of Higher Education noted that to achieve better results there is a need to improve the synergy between the higher education sector and other research sectors throughout countries and between the EHEA and the European Research Area. An overall European legislative framework to cover all qualifications issued as well as to simplify the existing recognition of degrees via the European Network of Information Centres in the European Region (ENIC)/National Recognition Information Centres in the European Union (NARIC) system was needed.

These problems and legal issues with respect to the recognition of qualifications within higher education as well as other levels of education in order to certify and facilitate the mobility of workers within the European labour market have also led to the development of the European Qualifications Framework (EQF). The EQF has combined the development of both the Bologna Process in higher education as well as the Copenhagen Process in vocational education. The EQF was developed with the intention of having National Qualifications Frameworks pegged to the EQF and thus facilitating the recognition of qualifications over the current system currently offered by the ENIC/ NARIC Networks.

It was also felt that there was a need for a legislative framework also in ensuring that universities within the EHEA offer a quality education. Ministers of Higher Education stressed the need for the development of mutually shared criteria and methodologies and agreed that these were to be developed by 2005 to guide national quality assurance systems. One finds that there is recognition of the importance on an education level on the harmonization of the standards to which the different universities with their diversity need to agree and adhere to. The legislative framework at European level in this case rests upon the setting up of quality assurance agencies and their roles in the accreditation of universities across Europe. 
The targets for the work set in Bergen thus included progress in: the implementation of the standards and guidelines for quality assurance as proposed in the European Association for Quality Assurance in Higher Education (ENQA) report (ENQA, 2005); implementation of the national qualifications frameworks for qualifications; the awarding and recognition of joint degrees, including at doctoral level; and the creation of opportunities for flexible learning paths in higher education, including procedures for the recognition of higher learning.

In the London Communiqué (European Ministers in Charge of Higher Education, 2007), Ministers reaffirmed their "commitment to increasing the compatibility and comparability of European Higher Education systems, whilst at the same time respecting their diversity" (pp. 1-2). They also "underlined the importance of strong institutions, which are diverse, adequately funded, autonomous and accountable". It was recognized that:

...the Standards and Guidelines for Quality Assurance in the EHEA adopted in Bergen (ESG) have been a powerful driver of change in relation to quality assurance. All countries have started to implement them and some have made substantial progress. External quality assurance in particular is much better developed than before. (p. 4)

On 4 March 2008, the European Quality Assurance Register for Higher Education (EQAR) was officially launched in Brussels to improve the quality assurance of European higher education and to promote greater student mobility (EQAR, 2008). The new Register was considered a landmark for European cooperation in quality assurance of higher education in the context of the Bologna Process reforms. Under the mandate of Higher Education Ministers from the forty-six countries taking part in the Bologna Process, the new register was established by the "E4 Group" comprising the ENQA, the European Students Union (ESU), the European University Association (EUA) and the European Association of Institutions in Higher Education (EURASHE). The aim of this new Register (EQAR) is to provide clear and objective information about trustworthy quality assurance agencies that are working in Europe. It also aims to help improve the quality of European higher education and to promote greater student mobility by increasing trust between higher education institutions. The register will provide a means for higher education institutions to choose between different agencies on the register. Inclusion on the EQAR is voluntary and is based on compliance with the European Standards and Guidelines for Quality Assurance adopted by European Education Ministers in 2005 .

\section{The Legislative Problems with the Pillars of the Bologna Process}

The legal framework of the Bologna Process (and the Lisbon Strategy) cannot work without a third level, beyond the national and the transnational ones. In fact the implementation of the entire system has to be completed by the rules set out by universities and other higher education establishments.

In general, EU law has included the role of the universities in legislation. Since the 1970 s, one finds several legal texts involving universities in programmes and other actions, particularly in the fields of research and education and training. This legal 
involvement was present many years before research and education became specifically part of European Community politics. The official legal recognition was obtained with the Unique Act and with the Treaty of Maastricht. ${ }^{1}$ In particular the programmes in the field of the higher education were established after two sentences of the European Court of Justice (ECJ) $(1985,1988)$ stating the right of free movement of the students.

When one sums up the Bologna Process and the establishment of the EHEA, one can identify two legislative aspects that have developed parallel to the process. These include the legal aspects related to issues concerning the recognition of qualifications and periods of study in other institutions, as well as recognition of degrees. These legal aspects have been covered mainly by the work of the Council of Europe, specifically the Lisbon Recognition Convention. In addition, one finds the publication of the EQF which will in the future; provide a new and easier system for reading qualifications across the EU and which may even supersede the function of the ENIC/NARIC Networks with respect to qualifications within the $\mathrm{EU}$.

The second legislative aspect is the quality assurance of higher education institutions. One finds documents or standards for quality assurance within the EHEA as well as the setting up of national legislation across European countries which require universities to undergo regular external quality assurance from registered quality assurance agencies. One thus finds national and European legislative structures regulating universities which themselves have to become legal bodies.

Today, according to the Bologna Process documents and other EU legal sources, universities participate in an active manner in the building of the EHEA. In fact they are entitled to: recognize degrees from other European and non European countries; recognize periods of studies on the ground of the ECTS and other credit systems; participate in the elaboration of codes of conduct, above all in bioethical matters; to participate in the elaboration of the policies at European and national levels, etc.

From the legal point of view the aforementioned activities are carried out mainly with academic regulations and agreements between universities (and between universities and other legal entities: research institutions, public bodies, enterprises).

The legal capacity and the juridical autonomy of European universities have been particularly enhanced by the aforementioned normative framework. In fact some functions of the universities under EU legal texts once were considered as an exclusive attribution of states, as the recognition of the diplomas issued abroad. Moreover the legal sources explicitly or implicitly recognized the full legal competence of universities, in order to adopt regulations or enter into all type of contracts. Further, such regulations and arrangements of universities can be considered as legal instruments to build the legal system. In fact, according to the White Paper on European Governance (European Commission, 2001), it is necessary to encourage a 'bottom-up' legal integration in the $\mathrm{EU}$, in application of the principle of subsidiarity. Many matters should be governed through decisive cooperation between the legal subjects involved in the application of the rules. Legal entities are not only required to ensure the effective application of the rules imposed by both EU institutions and member states, but, EU law provides that legal entities, on the ground of their autonomy, have the power to adopt rules integrating the legal system.

\footnotetext{
${ }^{1}$ See Art. 163 ss. with regard to research; Art. 149, par. 2, EC Treaty, for education; and Art. 150 par. 2, EC Treaty, for training.
} 
However, the new role of the university is encountering at least two kinds of difficulties. The first is that national laws may not be consistent with the aims of EU legal sources. In fact the processes relating to research and education matters are usually implemented with a 'soft law' approach. In these fields the rules are provided through the voluntary participation of states and operators, without a real compulsive action of the supranational Institutions (such as EU Institutions). This approach is very interesting because it is more flexible and respectful of legal and cultural diversity (a similar approach is used in other 'sensitive' matters such as bioethics). However the weakness of such a system is that states often preserve national dispositions which are not perfectly coherent with supranational processes. For example, in Italy there are some dispositions providing the competence of the Ministry of the Education, Universities and Research for the recognition of foreign degrees. ${ }^{2}$ Furthermore, Italian law seems to limit the contractual competence of the university in some arrangements (Cippitani and Colcelli, 2007). ${ }^{3}$

In many cases the internal regulations of universities are too old and do not take into consideration the transnational activities of universities (participation in EU programmes, establishment of joint degrees, recognition of diplomas, etc.).

The second type of problems is of both a legal and cultural nature. The legal instruments to implement the Bologna Process or the other European processes are unknown by the jurists and by legal consultants. In fact the legal literature ignores topics such as university regulations and agreements between universities to carry out research and education activities. Such arguments are usually considered only by the professionals or officials in charge of drawing up such texts. They cannot use any doctrine and jurisprudence and, only in some cases, are they able to find praxis and experience of other operators (as is the case in the format of Consortium Agreements of the Framework Programmes of Research and Technology Development). A further problem is that agreements between universities, in order to implement the Bologna Process, are not regulated by domestic law, or by international and European legal sources. Neither is it easy to exploit the general principles concerning contract law, because, generally speaking, they are focused on bilateral agreements dealing with economic exchanges. Also the actual process of harmonization of the law of the contract (Lando and Beale, 1999; Lando et al., 2003; Study Group on a European Civil Code and the Research Group on EC Private Law (Acquis Group), 2008) only take into consideration contracts concerning patrimonial matter and are usually contracts between two parties only.

Agreements between universities often involve several legal entities and are not usually addressed to deal with a bargain, but to allocate a budget of a project, recognize a diploma, establish a joint course, provide rules for experimental texts, or to allow for the exchange of researchers, etc.

It is thus necessary to study and to solve the above mentioned problems which risk preventing the correct functioning of the EHEA. In order to highlight potential legal problems which may arise, a number of potential scenarios are presented below. Such scenarios can include situations such as:

- Problems with periods of study abroad: it is a common occurrence for students to spend a period of time studying at a university other than their registered one as part of the ERASMUS student exchange programme. A situation may arise where after

\footnotetext{
${ }^{2}$ Art. 74 d.P.R. $382 / 1980$

${ }^{3}$ See Art. 66 and Art. 91-bis, d.P.R. n. 382/1980
} 
some time, the sending university may come to learn that the receiving institution has some irregularities in issuing ECTS credits: either tutors did not provide the programme of study as promised, or students failed to fulfil some obligations or were accused of misconduct which the receiving university failed to pick on at the appropriate time. What would happen to the ECTS gained by such students? Are their ECTS automatically cancelled or does the university need to go to court to remove any recognition of periods of study or possibly a qualification already issued? How is the receiving university which is in another Member State to be held accountable for any wrong doing or incompetence? Can compensation be sought?

- Problems with joint degrees: what can partner universities do if a joint Master's or Doctorate issued by more than three universities falters, or if the programme offered by one of the partners was not of the quality and standard required? Students may have been promised access to particular research teams and use of apparatus. What if access to such use of laboratory equipment and research teams is blocked by one of the partner universities? How can the other universities hold the third university accountable and ask for their obligations to be fulfilled? How can universities take legal steps to ensure that everybody fulfils their obligations, and to seek liability if a programme of study fails due to the behaviour of one of the institutions, when students have already paid for their studies? How do institutions resolve problems related to Intellectual Property Rights in doctorate joint degrees, should one university decide to keep all the rights itself as the work was done on its premises? What if a student is caught plagiarizing, or accused of misconduct during his/her studies? Who would be the main regulating and legal body to deal with a student of a joint degree programme?

- Collaborative research: one usually finds consortia agreements which deal with issues of property rights and intellectual property. But with large research programmes with as many as fourteen partners, legal regulation becomes problematic. As long as all the partners respect the consortium agreement, everything functions smoothly; however, what would happen if one of the partners decides to retain its intellectual property - what legal problems and procedures do the other partner universities, or also industry, have to deal with and which would be the best legislation to adopt - national or European? This will become particularly important as university funding becomes more market oriented and survival of research more closely linked to its intellectual property.

These are just a few examples of the problematic situations which may arise. If one considers the potential problems which may arise and which may require a legal solution or settlement, universities will quickly realize that the legal implications are many and may be problematic, mainly due to the lack of a legal perspective within the whole of the Bologna Process. It is thus high time that this aspect is taken on board by the relevant experts in order to avoid so many achievements breaking down.

\section{Conclusion}

The year 2010 had been targeted as the end of the Bologna Process and the beginning of the EHEA, an area which must continue to develop beyond 2010. The potential achievements in the Bologna Process were to lead the EHEA to be founded on the following structural elements: all participating countries to have a national framework 
of qualifications based on three cycles in higher education which prepare students for the labour market and for further competence building; all participating countries to have national quality assurance arrangements implementing an agreed set of standards and guidelines for the EHEA; and all higher education institutions in participating countries to recognize degrees and periods of studies according to the Lisbon Recognition Convention (Nyborg, 2005).

The EHEA has been conceptualized to: provide a social dimension to ensure the provision of equitable access into, progress and completion of higher education; support the employability of graduates capable of summoning knowledge and skills that make it possible to adapt to manifold situations; promote lifelong learning allowing movement up the qualifications framework and improving knowledge, skills and competences; as well as ensuring the attractiveness of European higher education as an attractive place to study and an attractive labour market for academics while maintaining the rich and diverse cultural heritage that European universities possess. The EHEA has to compete with the USA and a number of Far Eastern countries in investments and innovation.

This thus requires that the legislative framework does not only cater for European citizens, but also for the challenges (BFUG, 2008) in provision to non-EHEA countries promoting mobility; in dealing with global competitiveness; responding to demographic changes with an ageing society; and changing roles and responsibilities of universities. It becomes even more imperative that one avoids situations with a lack of legislative experience in problematic situations such as those highlighted, as it may jeopardize the work done for so long and across such a wide geographic area. There is thus a great need to call on experts in EU law and in international legal situations to look into the Bologna Process and the development of the EHEA such that they can ensure that there is a well developed legal structure as well as method of procedures for the potential different legal situations which may arise as a result of problems either between universities, universities and regulators, or universities and students/staff.

The greater internationalization of higher education is leading to a different role for universities. The Council of Europe stressed the national responsibilities with respect to the framework within which higher education is provided, in ensuring equal opportunities, such as in financing research and higher education. The state is thus becoming more of a regulator which means a redefinition of roles and responsibilities involved with respect to: quality development and assurance, funding framework, governance, institutional autonomy and accountability, diversity of missions and institutions, and the social dimension.

The BFUG (2008) report, however, also concludes that there is a need for a master plan for the future of the Bologna Process, which would require in the short-term the implementation of the new degree structure and to endorse it by establishing regulated professions, developing and implementing qualifications frameworks based on learning outcomes, involving stakeholders in the reform processes and ensuring quality. Mobility remains of great importance with curricula designed to better suit mobility as well as legal frameworks which promote staff mobility. It has also been recommended that a mobility code be drafted and data collected to monitor the internationalization of higher education as a benchmarking exercise.

No system can be proved to be a success before it is tried and tested. The Bologna Process can only be considered to have successfully built the EHEA once its fruits start to be borne. It would be a great pity if the legislative aspect of all the systems and procedures within the EHEA will limit its impact in a globalized world. It is for this reason 
that the legislative tools developed need to be piloted and scrutinized such that the hard collective effort will really lead to the realization of a functioning EHEA.

\section{References}

BARroso, J.M. "Strong Universities for Europe". Report prepared for the EUA Convention of European Education Institutions, Glasgow, 31 March 2005.

BFUG. Draft Bologna Beyond 2010 Report. London: Bologna Process Secretariat, 2008.

CIPPITANI, R. "L'Europa della conoscenza (la rìcerca e l'educazione al centro della costruzione comunitaria)" [The European Knowledge Society (Research and Education at the Centre of European Integration)], in T. Sediari, ed. Cultura dell'integrazione europea [The Culture of European Integration]. Torino: Giappichelli, 2005, p. 81.

CIPPITANI, R. and COLCELLI, V. "Diritto privato europeo e capacità negoziale delle università" [Private European Law and the Business Capacity of the University]. Rass. Giur. Umbra 2 (2007): 967 .

COMMISSION OF THE EUROPEAN COMMUNITIES. Communication from the Commission. Mobilising the Brainpower in Europe: Enabling Universities to Make Their Full Contribution to the Lisbon Strategy. Brussels: European Commission, 2005.

COMMISSION OF THE EUROPEAN COMMUNITIES. Communication from the Commission to the Council and European Parliament. Delivering on the Modernisation Agenda for Universities: Education, Research and Innovation. Brussels: European Commission, 2006.

COUNCIL OF EUROPE. Code of Good Practice in the Provision of Transnational Education. Adopted by the Lisbon Recognition Convention Committee at its second meeting, Riga, Latvia, 6 June, 2001.

COUNCIL OF EUROPE. Recommendation on Criteria and Procedures for the Assessment of Foreign Qualifications. Adopted by the Lisbon Recognition Convention Committee at its second meeting, Riga, Latvia, 6 June, 2001.

COUNCIL OF EUROPE. Recommendation on the Recognition of Joint Degrees. Adopted by the Committee of the Convention on the Recognition of Qualifications concerning Higher Education in the European Region, 9 June, 2004.

COUNCIL OF EUROPE. Council of Europe Higher Education Series Volume 3. Luxembourg: Council of Europe Publishing, 2005.

COUNCIL OF EUROPE and UNESCO. Convention on the Recognition of Qualifications Concerning Higher Education in the European Region. [location]: Council of Europe and UNESCO, 1997.

STUdy GRoup on a EuRopeAN CIVIL CODE AND THE RESEARCH GROUP ON EC PRIVATE LAW (ACQUIS Group). Principles, Definitions and Model Rules of Etropean Private Law - Draft Common Frame of Reference, Interim Outline Edition, ed. C. von Bar, E. Clive, H. SchulteNölke, H. Beale, J. Herre, J. Huet, P. Schlechtriem, M. Storme, S. Swann, P. Varul, A. Veneziano, and F. Zoll. Munich: Sellier, 2008.

European Court of Justice (ECJ). Gravier/Ville de Liège, Rec. 1985, 13 February 1985, p. 593.

European Court of Justice (ECJ). Blaizot/Universite de Liège and others, Rec. 1988, 2 February 1988, p. 379.

ENQA. "Standards and Guidelines for Quality Assurance in the European Higher Education Area". ENQA report to Ministers meeting, Bergen. Retrieved in March 2009, from <http:// www.enqa.eu/files/ENQA\%20Bergen\%20Report.pdf $>, 2005$.

EQAR. "Europe launches Quality Assurance Register for Higher Education". Press release. Retrieved in March 2009, from <http://www.eua.be/fileadmin/user_upload/files/Press/EQARlaunchpr-FINAL.pdf>, 2008

EUROPEAN COMMISSION. White Paper on Growth, Competitiveness and Employment: The Challenges and Ways Forward into the 21st Century. Brussels: European Commission, 1993. 
EuRoPEAN COMMISSION. Green Paper on Innovation. Brussels: European Commission, 1995a. European COMMISSION. White Paper on Education and Training: Teaching and Learning, Towards a Learning Society. Brussels: European Commission, 1995b.

EUROPEAN COMMISSION. White Paper on the European Governance. Brussels: European Commission, 2001.

EUROPEAN COMMISSION. Europe Needs Modernised Universities, Says European Commission. Brussels: European Commission, 2006.

EUROPEAN MINISTERS IN CHARGE OF HIGHER EDUCATION. Joint Declaration on the Harmonisation of the Architecture of European Higher Education System [Sorbonne Declaration]. Sorbonne, 1998.

European Ministers IN CHARge of Higher EduCATION. Joint Declaration of the European Ministers of Education [The Bologna Declaration]. Bologna, 1999.

EUROPEAN MINISTERS IN CHARGE OF HIGHER EDUCATION. "Towards the European Higher Education Area". Communique of the Meeting of the European Ministers in charge of Higher Education, Prague, 19 May 2001.

European Ministers In Charge of Higher Education. "Realising the European Higher Education Area". Communiqué of the Conference of the European Ministers in Charge of Higher Education, Berlin, 19 September 2003.

European Ministers IN Charge of Higher EduCation. "The European Higher Education Area - Achieving the Goals". Communiqué of the Conference of the European Ministers in Charge of Higher Education, Bergen, 19-20 May 2005.

EUROPEAN MINISTERS IN CHARGE OF HIGHER EDUCATION. "Towards the European Higher Education Area: Responding to Challenges in a Globalised World". Communique of the Conference of the European Ministers in Charge of Higher Education, London, 18 May 2007. Retrieved on , from <http://www.cepes.ro/information_services/sources/on_line/2007London Communique.en.pdf $>, 2007$.

FIGEL, J. "Strong Universities for Europe". Paper presented at the EUA Convention of European Education Institutions, Glasgow, 31 March, 2005.

Lando, O. and Beale, H., eds. Principles of European Contract Law Parts I and II. Prepared by the Commission on European Contract Law. The Hague: European Commission, 1999.

Lando, O., Clive, E., PrüM, A. and Zimmermann, R., eds. Principles of European Contract Law Part III. The Hague: European Commission, 2003.

MORIN E. Pensare L'Europa [Thinking Europe]. Milano: Feltrinelli, 1990.

NYBORG, P. "A Vision for 2010 and Beyond". Paper presented at the ESIB Seminar, "Bologna, Bergen and Beyond", Bergen, 11-13 May 2005.

RUBERTI, A. Uno Spazio Europeo della Scienza [The European Scientific Area]. Firenze: Guinti, 1995. 